\title{
Impact of Thyroglobulin on Survival and Prognosis of Differentiated Thyroid Cancer
}

\author{
Hanan Ahmed Wahba ${ }^{1}$, Hend Ahmed El-Hadaad ${ }^{1}$, Abeer Hussien Anter ${ }^{1}$, Alaa M. Wafa ${ }^{2}$, \\ Ahmed Negm ${ }^{3}$ \\ ${ }^{1}$ Clinical Oncology \& Nuclear Medicine Department, Faculty of Medicine, Mansoura University Hospital, Mansoura, Egypt \\ ${ }^{2}$ Internal Medicine Department, Faculty of Medicine, Mansoura University Hospital, Mansoura, Egypt \\ ${ }^{3}$ General Surgery Department, Faculty of Medicine, Mansoura University Hospital, Mansoura, Egypt \\ Email: ^hend_am@mans.edu.eg
}

How to cite this paper: Wahba, H.A., El-Hadaad, H.A., Anter, A.H., Wafa, A.M. and Negm, A. (2018) Impact of Thyroglobulin on Survival and Prognosis of Differentiated Thyroid Cancer. Journal of Cancer Therapy, 9, 706-713.

https://doi.org/10.4236/jct.2018.99058

Received: August 9, 2018

Accepted: September 8, 2018

Published: September 11, 2018

Copyright (c) 2018 by authors and Scientific Research Publishing Inc. This work is licensed under the Creative Commons Attribution International License (CC BY 4.0)

http://creativecommons.org/licenses/by/4.0/

\begin{abstract}
Proper assessment of risk factors contributes to the principle management of differentiated thyroid carcinoma post operatively. Aim of the study: to investigate the effect of Thyroglobulin ( $\mathrm{Tg}$ ) levels on prognosis together with other risk factors for Differentiated Thyroid Cancer (DTC). Patients and methods: Medical records of all patients with DTC presented to Clinical Oncology and Nuclear Medicine Department referred from Diabetes \& Endocrine unit (Internal Medicine Hospital) and Surgery Department Mansoura University from 2011-2016 were retrospectively reviewed. Patients with distant metastasis or who lost follow-up were excluded. So data of 220 patients were analyzed. Data collected included pre-surgical assessment, also surgical interference either total or near total thyroidectomy with or without lymph node neck dissection were reviewed. Different prognostic factors that affect progression free survival (PFS) include age, umorsize, ymph node status, ex, multifocality, capsular infiltration, vascular invasion and Tg level were evaluated through multivariate analysis. Results: Most of the patients included were $<45$ years (69.1\%). Incidence of the disease was higher in female (80\%) with papillary type predominance $(80.9 \%)$. About $59.5 \%$ of cases presented with tumor size $\leq 2 \mathrm{~cm}$ and multifocality was reported in $13.6 \%$. While $30 \%$ had lymph node metastasis, $11 \%$ had vascular invasion. Capsular infiltration was observed in $15 \%$ and most of them showed $\mathrm{Tg}$ level $\leq 10 \mathrm{ng} / \mathrm{ml}$ (68.2\%). About $70 \%$ received ablative radioiodine. The 5-year Progression Free Survival (PFS) was $85 \%$. On multivariate analysis of variable prognostic factors on PFS, we found that tumor size, age, lymph node status, capsular infiltration, $\mathrm{Tg}$ level and vascular invasion significantly affected PFS $(\mathrm{P}=0.01,0.005,0.004,0.005$, $0.02,0.003)$ respectively. While sex, pathological type and multifocality were not $(\mathrm{P}=0.9,0.4,0.6)$ respectively. Conclusion: Postoperative Tg level is a statistically significant prognostic factor together with other risk factors.
\end{abstract}




\section{Keywords}

Thyroglobulin, Thyroid Cancer, Differentiated Thyroid Cancer, Risky Factors

\section{Introduction}

Differentiated thyroid carcinoma (DTC) includes papillary thyroid carcinoma which is the most common thyroid neoplasm $(80 \%-90 \%)$ followed by the follicular one $(10 \%-40 \%)$ [1]. DTC has a good prognosis with 10 year survival rates of $85 \%-93 \%$ [2]. Thyroglobulin ( $\mathrm{Tg}$ ) is a glycoprotein produced only by follicular cells of the thyroid so used as a marker to monitor the thyroid diseases [3] [4].

Treatment of DTC is surgery and radioactive iodine; nearly $80 \%$ of patients recover after first treatment [5]. Despite most recurrences of the disease occurred within the first five years, it was observed also after 45 years [6].

Prognostic factors enable us to identify patients with high risk of disease recurrence and allow personalization of method of treatment depending on patient's risk factors [7].

After surgery, Tg levels are affected by the presence of remaining thyroid tissue. It was found that $1 \mathrm{~g}$ of thyroid tissue lead to increase to Tg level by approximately $1 \mu / \mathrm{L}$ [8]. It was reported that $\mathrm{Tg}$ levels could be a predictor for progressive or metastatic disease during follow-up period of patients with DTC [9] [10] [11].

This retrospective study was conducted to investigate the effect of Tg levels on prognosis together with other risk factors for DTC.

\section{Patients and Methods}

Medical records of all patients with DTC presented to Clinical Oncology and Nuclear Medicine department, referred from Diabetes \& Endocrine unit (Internal medicine hospital) and surgery department Mansoura University from 2011-2016 were retrospectively reviewed. Patients with distant metastasis or who lost follow-up were excluded. So data of 220 patients were analyzed.

Data collected included presurgical assessment as clinical general and neck examination of the patients, radiological investigations as neck ultrasound (US), thoracic or neck computed tomography (CT), laboratory tests as T3, T4, TSH levels and histopathological type.

Also surgical interference either total or near total thyroidectomy with or without lymph node neck dissection were reviewed. Staging was evaluated according to AJCC staging system [12].

Postoperative follow-up of the patients were carried out every six months through clinical examination, neck US, levels of T3, T4, TSH, Tg and 5 mci of

${ }^{131}$ I whole body scan (WBS) when TSH level was higher than $30 \mathrm{IU} / \mathrm{ml}$. 
If the patient was in need for ablative dose of radioactive ${ }^{131} \mathrm{I}$, he received 50 150 mci according to risk stratification by the American Thyroid Association (ATA) [13] and WBS was performed 72 hours follow ${ }^{131}$ I ingestion.

Different prognostic factors affect progression free survival (PFS) include age, tumorsize, lymph node status, sex, multifocality, capsular infiltration, vascular invasion and Tg level were evaluated through multivariate analysis.

PFS was calculated from date of surgery to date of disease progression.

Statistical methods: IBM SPSS was used for statistical analysis, Chi square test used as a test of significance, $\mathrm{P}<0.05$ considered significant. Kaplan-Meier test was used for survival function.

Ethical consideration: This study was approved by the Medical Ethics Committee and the study was carried out in accordance with the Declaration of Helsinki.

\section{Results}

Characteristics of 220 patients involved in this study are summarized in Table 1. Most of them were $<45$ years (69.1\%). As suspected incidence of the disease was higher in female $(80 \%)$; with papillary type predominance $(80.9 \%)$. About $59.5 \%$ of cases presented with tumor size $\leq 2 \mathrm{~cm}$ and multifocality was reported in $13.6 \%$. While $30 \%$ had lymph node metastasis, $11 \%$ had vascular invasion. Capsular infiltration was observed in $15 \%$ and most of them showed Tg level $\leq 10$ $\mathrm{ng} / \mathrm{ml}(68.2 \%)$. About $70 \%$ of patients received ablative radioactive Iodine.

5-year progression free survival (PFS) among studied cases was 85\% Figure 1.

On multivariate analysis of variable prognostic factors affecting PFS ;we found that tumor size, age, lymph node status, capsular infiltration, Tg level and vascular invasion significantly affected PFS $(P=0.01,0.005,0.004,0.005,0.02$, $0.003)$ respectively. While sex, pathological type and multifocality were not $(\mathrm{P}=$ $0.9,0.4,0.6$ ) respectively (Table 2 ).

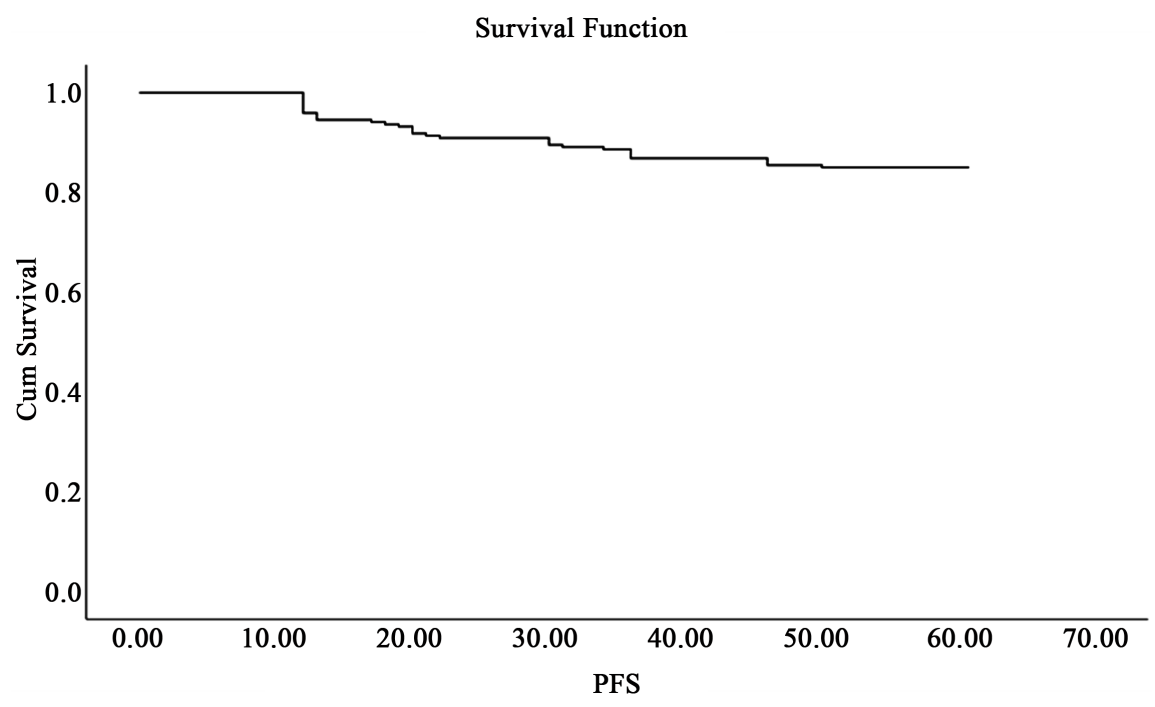

Figure 1. Progression Free Survival (PFS) of studied cases. 
Table 1. Patients characteristics.

\begin{tabular}{|c|c|c|}
\hline Character & $\mathrm{N}$ & $\%$ \\
\hline \multicolumn{3}{|l|}{ Age (years) } \\
\hline$<45$ & 152 & 69.1 \\
\hline$\geq 45$ & 68 & 30.9 \\
\hline \multicolumn{3}{|l|}{ Gender } \\
\hline Male & 44 & 20 \\
\hline Female & 176 & 80 \\
\hline \multicolumn{3}{|l|}{ Pathology } \\
\hline Papillary & 178 & 80.9 \\
\hline Follicular & 42 & 19.1 \\
\hline \multicolumn{3}{|l|}{ Tumor size } \\
\hline$\leq 2 \mathrm{~cm}$ & 131 & 59.5 \\
\hline$>2 \mathrm{~cm}$ & 89 & 40.5 \\
\hline \multicolumn{3}{|l|}{ Multifocality } \\
\hline Yes & 30 & 13.6 \\
\hline No & 190 & 86.4 \\
\hline \multicolumn{3}{|c|}{ Lymph node metastasis } \\
\hline Yes & 66 & 30 \\
\hline No & 154 & 70 \\
\hline \multicolumn{3}{|c|}{ Capsular infiltration } \\
\hline Yes & 33 & 15 \\
\hline No & 187 & 85 \\
\hline \multicolumn{3}{|c|}{ Vascular invasion } \\
\hline Yes & 24 & 10.9 \\
\hline No & 196 & 89.1 \\
\hline \multicolumn{3}{|l|}{ Tg level } \\
\hline$\leq 10 \mathrm{ng} / \mathrm{ml}$ & 150 & 68.2 \\
\hline$>10 \mathrm{ng} / \mathrm{ml}$ & 70 & 31.8 \\
\hline
\end{tabular}

Table 2. Multivariate analysis of risk factors.

\begin{tabular}{ccc}
\hline Character & Recurrence rate & P \\
\hline Age (years) & $6 / 152(3.9 \%)$ & 0.005 \\
$<45$ & $10 / 68(14.7 \%)$ & \\
$\geq 45$ & & \\
Gender & $4 / 44(9.1 \%)$ & 0.9 \\
Male & $15 / 176(8.5 \%)$ & \\
Female & & \\
\hline
\end{tabular}




\section{Continued}

\begin{tabular}{|c|c|c|}
\hline Pathology & & \multirow[b]{2}{*}{0.4} \\
\hline Follicular & $\begin{array}{c}15 / 178(8.4 \%) \\
5 / 42(11.9 \%)\end{array}$ & \\
\hline \multicolumn{3}{|l|}{ Tumor size } \\
\hline $\begin{array}{l}\leq 2 \mathrm{~cm} \\
>2 \mathrm{~cm}\end{array}$ & $\begin{array}{c}5 / 131(3.8 \%) \\
11 / 89(12.3 \%)\end{array}$ & 0.01 \\
\hline \multicolumn{3}{|l|}{ 5-Multifocality } \\
\hline Yes & $\begin{array}{l}2 / 30(6.6 \%) \\
9 / 190(4.7 \%)\end{array}$ & 0.6 \\
\hline \multicolumn{3}{|c|}{ Lymph node metastasis } \\
\hline $\begin{array}{l}\text { Yes } \\
\text { No }\end{array}$ & $\begin{array}{l}6 / 66(9.1 \%) \\
2 / 154(1.3 \%)\end{array}$ & 0.004 \\
\hline \multicolumn{3}{|c|}{ Capsular infiltration } \\
\hline $\begin{array}{l}\text { Yes } \\
\text { No }\end{array}$ & $\begin{array}{l}6 / 33(18.1 \%) \\
9 / 187(4.8 \%)\end{array}$ & 0.005 \\
\hline \multicolumn{3}{|c|}{ Vascular invasion } \\
\hline Yes & $\begin{array}{c}5 / 24(20.8 \%) \\
10 / 196(5.1 \%)\end{array}$ & 0.003 \\
\hline \multicolumn{3}{|l|}{ Tg level } \\
\hline $\begin{array}{l}\leq 10 \mathrm{ng} / \mathrm{ml} \\
>10 \mathrm{ng} / \mathrm{ml}\end{array}$ & $8 / 150(5.3 \%)$ & 0.02 \\
\hline
\end{tabular}

\section{Discussion}

Relapse of DTC is a major clinical oncological problem either local or distant relapse in which lung, bone and brain are the most common sites [14].

In our study, we found age at diagnosis is a strong prognostic factor for recurrence which is comparable to that reported by Krajewska et al. [15]. This was explained by association of more aggressive behavior of tumors in old age or age-related factors as immune status and nutrition [16]. However, Ozkan et al. [17] did not find this relation.

Similar to our results; it was reported that female patients had better prognosis than male but the difference is insignificant [18]. We observed that papillary thyroid cancer had significantly better prognosis than follicular type, this may be attributed to different biological behavior between both types as follicular variant developed distant metastasis more than papillary one [19].

As we found in our studied cases; negative impact of thyroid capsular infiltration and vascular invasion on DFS were emphasized by some studies [20] [21] [22].

Multifocality had no impact on DFS in our series, comparable to others [6] [23], while Gulcelik et al. [22] reported significant impact. As reported by others 
[15] [24] [25], large tumor size and presence of lymph node metastasis at presentation were related to higher risk of relapse in our study.

Ronga et al. [26] mentioned that postoperative $\mathrm{Tg}$ value can result in early detection of metastasis regardless presence of thyroid remnant.

It was demonstrated that subjects with postoperative $\mathrm{Tg}$ value $<10 \mathrm{ng} / \mathrm{ml}$ showed a $6 \%$ likelihood of persistant DTC while those with value $>10 \mathrm{ng} / \mathrm{ml}$ had $47 \%$ [27].

It was observed that postoperative $\mathrm{Tg}$ concentration was higher in male [7] this may be attributed to poorer prognosis in male.

Toubeau et al. [11] recommended that patients with high postoperative $\mathrm{Tg}$ level or lymph node metastasis should be carefully followed-up. Hall et al. [28] demonstrated that patients with initial high tumor stage and $\mathrm{Tg}$ value $>20$ $\mathrm{ng} / \mathrm{ml}$ measured 3 months postoperatively may have disease recurrence. Some studies reported that $\mathrm{Tg}$ value after surgery $\geq 10 \mathrm{ng} / \mathrm{ml}$ are important marker to predict prognosis in DTC [15] [29]. Malandino et al. [30] recommended that Tg level may be sufficient to assess the risk-adapted treatment in DTC. In our patients level of $\mathrm{Tg}>10 \mathrm{ng} / \mathrm{ml}$ was associated with significantly poorer PFS.

The 5-year PFS was $85 \%$ in our study comparable to that reported in other studies [7] [11].

\section{Conclusion}

In this retrospective study, we found that postoperative $\mathrm{Tg}$ level is a statistically significant prognostic factor together with other risk factors.

\section{Acknowledgements}

This research received no specific grant from any funding agency in the public, commercial, or not-for-profit sectors. The authors report no conflicts of interest. All authors have contributed significantly, and that all authors are in agreement with the content of the manuscript.

\section{Conflicts of Interest}

The authors declare no conflicts of interest regarding the publication of this paper.

\section{References}

[1] Eustatia-Rutten, C.F., Corssmit, E.P., Biermasz, N.R., et al. (2006) Survival and Death Causes in Differentiated Thyroid Carcinoma. The Journal of Clinical Endocrinology \& Metabolism, 91, 313-319. https://doi.org/10.1210/jc.2005-1322

[2] Hundahl, S.A., Fleming, I.D., Fremgen, A.M., et al. (1985) A National Cancer Data Base Report on 53,856 Cases of Thyroid Carcinoma Treated in the U. S. Cancer, 83, 2638-2648.

https://doi.org/10.1002/(SICI)1097-0142(19981215)83:12<2638::AID-CNCR31>3.0. CO;2-1

[3] Torlontano, M., Crocetti, U., Augello, G., et al. (2006) Comparative Evaluation of Recombitant Human Thyrotrobin-Stimulated Thyroglobulin Levels, 131I Whole-Body 
Scintigraphy and Neck Ultrasound in the Follow-Up of Patients with Papillary Thyroid Microcarcinoma Who Have Not Undergone Radioiodine Therapy. The Journal of Clinical Endocrinology \& Metabolism, 91, 60-63. https://doi.org/10.1210/jc.2005-1185

[4] Makarewicz, J. and Lewin'ski, A. (2004) Prognostic Factors in Patients with Differentiated Thyroid Carcinoma. PostepyHig Med Dosw (Online), 58, 514-521.

[5] Mazzaferri, E.L. and Kloos, R.T. (2001) Current Approaches to Primary Therapy for Papillary and Follicular Thyroid Cancer. The Journal of Clinical Endocrinology \& Metabolism, 86, 1447-1463. https://doi.org/10.1210/jcem.86.4.7407

[6] Leung, A.M., Dave, S., Lee, S., et al. (2011) Factors Determining the Persistence or Recurrence of Well-Differentiated Thyroid Cancer Treated by Thyroidectomy and/or Radioiodine in the Boston, Massachusettsarea: A Retrospective Chart Review. Thyroid Research, 4, 9. https://doi.org/10.1186/1756-6614-4-9

[7] Juszczyk, K.G. and Kowalska, A. (2015) Comparison of the Usefulness of Post-Ablative and Post-Operative Thyroglobulin Concentration Measuring in Prognostic Assessment of Patients with Differentiated Thyroid Cancer. Endokrynologia Polska, 66, 486-494.

[8] Baloch, Z., Carayon, P., Conto-Devolex, B., et al. (2013) Laboratory Medicine Practice Guidelines. Laboratory Support for the Diagnosis and Monitoring of Thyroid Disease. Thyroid, 13, 3-126.

[9] Sawaka, A.M., Orlov, S., Gelberg, J., et al. (2008) Prognostic Value of Postsurgical Stimulated Thyroglobulin Levels after Initial Radioactive Iodine Therapy in Well-Differentiated Thyroid Carcinoma. Head Neck, 30, 693-700. https://doi.org/10.1002/hed.20755

[10] Heemstra, K.A., Liu, Y.Y., (2007) Stokkel Metal. Serum Thyroglobulin Concentration Predict Disease-Free Remission and Death in Differentiated Thyroid Carcinoma. ClinEndocrinol (Oxf), 66, 58-64.

[11] Toubeau, M., Touzery, C., Arveux, P., et al. (2004) Predictive Value for Disease Progression of Serum Thyroglobulin Levels Measured in the Postoperative Period and after 131I Ablation Therapy in Patients with Differentiated Thyroid Cancer. Journal of Nuclear Medicine, 45, 988-994.

[12] Stephen, B. and Carolyn, C. (2010) The American Joint Committee on Cancer: The $7^{\text {th }}$ Edition of the AJCC Cancer Staging Manual and the Future of TNM. Annuals Surgical Oncology, 17, 1471-1474.

[13] Haugen, B.R., Alexander, E.K., Bible, K.C., et al. (2016) 2015 American Thyroid Association Management Guidelines for Adult Patients with Thyroid Nodules and Differentiated Thyroid Cancer: The American Thyroid Association Guidelines Task Force on Thyroid Nodules and Differentiated Thyroid Cancer. Thyroid, 26, 1-133. https://doi.org/10.1089/thy.2015.0020

[14] Ruegemer, J., Hay, I., Bergstraih, E., et al. (1988) Distant Metastasis in Differentiated Thyroid Carcinoma: A Multivariate Analysis of Prognostic Variables. The Journal of Clinical Endocrinology \& Metabolism, 67, 501-508. https://doi.org/10.1210/jcem-67-3-501

[15] Krajewska, J., Jarzab, M., Czarniecka, A., et al. (2106) Ongoing Risk Stratification for Differentiated Thyroid Cancer (DTC)-Stimulated Serum Thyroglobulin (Tg) before Radioiodine (RAI) Ablation, the Most Potent Risk Factor of Cancer Recurrence in M0 Patients. Endokrynologia Polska, 67, 2-10. https://doi.org/10.5603/EP.2016.0001

[16] Ceccarelli, C., Pacini, F., Lippi, F., et al. (1988) Thyroid Cancer in Children and 
Adolescents. Surgery, 104, 1143-1148.

[17] Ozkan, E., Soydal, C., Araz, M., et al. (2017) May Preablative Thyroglobulin Level Be a Prognostic Indicator for Papillary Thyroid Cancer? Clinical and Medical Investigations, 2, 1-5. https://doi.org/10.15761/CMI.1000122

[18] National Cancer Institute (2010) Surveillance, Epidemiology and End Results Program (SEER) Cancer Statistics Review, 1975-2007. National Cancer Institute, Besthesda.

[19] Sisson, J., Giordano, T., Jamadar, D., et al. (1996) 131-I Treatment of Micronodular Pulmonary Metastasis from Papillary Thyroid Carcinoma. Cancer, 78, 2184-2192. https://doi.org/10.1002/(SICI)1097-0142(19961115)78:10<2184::AID-CNCR21>3.0. CO;2-U

[20] Jukkola, A., Bloigu, R., Ebeling, T., et al. (2004) Prognostic Factors in Differentiated Thyroid Carcinomas and Their Implications for Current Staging Classifications. Endocrine-Related Cancer, 11, 571-579. https://doi.org/10.1677/erc.1.00826

[21] D’Avanzo, A., Treseler, P., Ituarte, P.H.G., et al. (2004) Follicular Thyroid Carcinoma: Histology and Prognosis. Cancer, 100, 1123-1129.

https://doi.org/10.1002/cncr.20081

[22] Gulcelik, M.A., Gulcelik, N.E., Kuru, B., et al. (2007) Prognostic Factors Determining Survival in Differentiated Thyroid Cancer. Journal of Surgical Oncology, 96, 598-604. https://doi.org/10.1002/jso.20845

[23] Lang, B.H., Wong, K.P., Cheung, C.Y., et al. (2013) Evaluating the Prognostic Factors Associated with Cancer-Specific Survival of Differentiated Thyroid Carcinoma Presenting with Distant Metastasis. Annals of Surgical Oncology, 20, 1329-1335. https://doi.org/10.1245/s10434-012-2711-x

[24] Machens, A., Hinze, R., Thomusch, O., et al. (2001) Pattern of Nodal Metastasis for Primary and Reoperative Thyroid Cancer. World Journal of Surgery, 16, 22-28.

[25] Lundgren, C.I., Hall, P., Dickman, P.W., et al. (2006) Clinically Significant Prognostic Factors for Differentiated Thyroid Carcinoma: A Population-Based, Nested Case-Control Study. Cancer, 106, 524-531. https://doi.org/10.1002/cncr.21653

[26] Ronga, G., Filesi, M., Ventroni, G., et al. (1999) Value of the First Serum Thyroglobulin Level after Total Thyroidectomy for the Diagnosis of Metastasis from Differentiated Thyroid Carcinoma. European Journal of Nuclear Medicine, 26, 1448-1452. https://doi.org/10.1007/s002590050477

[27] Webb, R.C., Howard, R.S., Stojadinovic, A., et al. (2012) The Utility of Serum Thyroglobulin Measurement at the Time of Remenant Ablation for Predicting Disease-Free Status in Patients with Differentiated Thyroid Cancer: A Mata-Analysis Involving 3947. The Journal of Clinical Endocrinology \& Metabolism, 97, 2754-2763. https://doi.org/10.1210/jc.2012-1533

[28] Hall, F.T., Beasly, N.J., Eski, S.J., et al. (2003) Predictive Value of Serum Thyroglobulin after Surgery for Thyroid Carcinoma. Laryngoscope, 113, 77-81. https://doi.org/10.1097/00005537-200301000-00014

[29] Lin, J.D., Huang, M.J., Hsu, B.R., et al. (2002) Significance of Postoperative Serum Thyroglobulin Levels in Patients with Papillary and Follicular Thyroid Carcinomas. Journal of Surgical Oncology, 80, 45-51. https://doi.org/10.1002/jso.10089

[30] Malandrino, P., Latina, A., Marescalco, S., et al. (2011) Risk-Adapted Management of Differentiated Thyroid Cancer Assessed by a Sensitive Measurement of Basal Serum Thyroglobulin. The Journal of Clinical Endocrinology \& Metabolism, 96, 1703-1709. https://doi.org/10.1210/jc.2010-2695 